\title{
Analysis of the Management of High-level Overseas Talents Working in the State-owned Enterprises
}

\author{
Liang-Yu WANG* \\ Beijing Aeronautical Science\&Technology Research Institute of COMAC, Beijing, China \\ goodjade@163.com \\ ${ }^{*}$ Corresponding author
}

Keywords: Human resource planning, Motivate system management, State-owed enterprises.

\begin{abstract}
This paper analyzes human resource planning, motivate system, achievement assessment, training program and so on to do a deep analysis of the management of high-level overseas talents working in the state-owned enterprises, and attempt to explore the optimization of the management of talents.
\end{abstract}

\section{Introduction}

In recent years, China has introduced lots of high-level overseas talents to work and set up a business in China. With the rapid development of the country, most of the enterprises have seized the opportunity. Taking the advantage of policies and measures, they introduced lots of overseas talents to enrich the talents for further innovative development and find more leaders to internationalization of the enterprise [1]. However, with more and more overseas talents returning back home, a series of problems have arisen. Such as the talents did not suit the local situation, they hardly played an important role and there is problem of brain drain. Therefore, the enterprises need to consider more about how to introduce appropriate talents, how to make better use of them and how to retain them. Establishing a more efficient and practical mechanism has become the key to improve the management of high-level overseas talents. For state-owned enterprises, the problem of the management of the overseas talents is very important for the national economy and technology development. Therefore in this paper, we will analyze this problem and try to propose some solutions.

\section{Current situation and the challenge in the state-owned enterprise}

\section{Difficulty to introduce talents}

It is very hard to introduce full-time leading talents, especially professors of world well-known colleges and universities. In general, they play multiple roles in the universities and relevant departments and have stable social life and family relationship. There are a lot of resistance and risk for them to return. The information of the human resources is always in disorder which increases the difficult to introduce talents. For example, for talents in the international famous enterprises, if we just release recruitment information by internet, the chance to attract them and communicate with them is very slim. Otherwise, level of the introduced talents is uneven. Through the information of $\mathrm{CV}$ and preliminary communication, it is hard to see their abilities and levels.

\section{Resistance to make use of talents}

We still need to discuss how to take advantage of them. The introduced experts have a strong theoretical basis and a lot of practical experience in the relevant discipline; especially, they are very insightful in the perspective and the basis discipline. But their functions in the research and production projects, establishment of discipline and group need further excavation and reflection. Therefore, how to take advantage of overseas talents as a bridge to the international frontier and a leader has become the key part of introduction. 
The adaption of the overseas talents to the research condition in China needs more consideration. With the characteristic of having high-level research work and being long time abroad, they were situated in the scientific and technological frontier and at the top of some industries. They have advanced knowledge and technology; at the same time they are used to the foreign innovative mechanism. Therefore, there will be some maladjustment in the Chinese research atmosphere. The maladjustment in culture, mechanism and policies will restrict the rapid and sound development of the overseas talents.

\section{Trouble to retain talents}

Due to the unfamiliar to the research condition, work condition and the mechanism of management of the technology, the overseas talents are usually hard to play a role as they think and hard to motivate their innovative abilities. Consequently, there are some brain drain phenomena in many enterprises.

\section{Analysis of the problem in the mechanism about the management of high-level overseas talents working in the state-owned enterprises}

\section{Difference philosophy between foreign countries and China}

The human resource management planning is not enough. According the survey, the management of the human resource in international enterprise puts particular emphasis on the planning of human resource [2]. For example, for the management pattern of human resource in international enterprises, most of them adopt the service delivery model which means that HRSSC (Human resources Shared service center), HRBP (human resource business partner) and HRMEC (Human resource management experts' center) form a triangle pattern. In detail, HRBP is formed by the personnel of each business unit and it gives assistance to the planning of human resource of each business unit; HRSSC deals with the daily operations including part of outsourcing business and the service for the employee, such as the relationship between the employees, management of salary, social security payment and so on. The experts' center is the department which solves all kind of human resource issues which are internal or external. However, as the survey shows, most of state-owned enterprises in China do not pay enough attention to the planning of human resource. Their key daily operations are recruitment, training program, performance appraisal, entrusted salary payment and social security payment. For the overall requirement, planning and distribution of human resource of the enterprises, it is lack of scientific method.

The requirement of talents is not explicit. We know that for international enterprises, the department of human resource will calculate the requirement and the supply in every stage, and analyze, predict the further work. According this, they will recruit relevant employee. However, for Chinese state-owned enterprises, recently, with the introduction of talents improving, a number of overseas talents have returned, while the planning and calculation of requirement of talents is not enough. The enterprises have not scientific analysis and prediction for the post left and talent needed. The direction of recruitment is not clear, consequently it is not good for the introduction and it still has a long distance between foreign management of human resource and Chinese management of human resource.

\section{Vague of responsibility and lacking of security in indemnity}

According to the survey in recruitment of high-level overseas talents, we know that there are three types of posts for talents: expert jobs, such as Chief Technology Officer, senior expert, senior science adviser and so on; middle-level cadre jobs, such as the chef or the vice chef in the department and so on; managers, such as the chief engineer, director and so on. Besides the responsibility is broad, lack of detail, standard and explicit responsibility. For the first type of jobs, the right and the responsibility may not be matched. In addition, it will appear lack of the security in indemnity and the equipment for whole group which will lead to a disorder of human resource and the talents will lose their functions [3].

\section{Lack of the awareness for training for high-level overseas talents}

High-level overseas talents are at the international front in academic attainments, social status, advanced ideas and so on. When they come back, they always become the leaders and the directors in the 
enterprises. But many enterprises do not have the training program for them. Because of this illusion, talents do not situate to conditions in China which leads to the brain drain phenomenon

\section{Imperfectness of motivation system}

We are on the first stage in exploring the way of introduction of overseas talents. Most of the enterprises in China have not a sound motivation system. For example, for government, it set up the Government Friendship Award, while for enterprises, almost none of them have relevant motivation system to motivate the enthusiasm of overseas talents which probably becomes the main reason for the brain drain.

\section{The over emphasis of the short-term achievement assessment}

With a great number of overseas talents coming back, enterprises have high hopes of them. They hope the talents could produce the best possible result which usually leads to over emphasis of short-term achievement assessment and neglection in long-term development of overseas talents. Especially, for the leading talents in basis and in international frontier, we should consider more on innovative abilities in a long period [4].

\section{Exploration of the optimization for management of overseas talents}

\section{More attention for scientific human resource planning, introduction of talents by direction of requirement of post}

Our state-owned enterprises are on the way toward the internationalization, therefore we need to learn the international philosophy for management of human resource and pay more attention to strategic and scientific human resource planning with the analysis method including trend analysis, a scatter diagram method, ratio analysis. Before scientific prediction and planning of talents, we should analyze the requirement and supply of post. At the same time, we could use pilot project and try to the international service pattern of management of human resource. We could try to put the emphasis on strategic planning of human resource management and plan for the enterprises' long-term strategy. The change of pattern about international human resource mode is not universal and once for all. There will appear a lot of problems in pilot project and enterprises need to implement relevant measures adapted to their own condition [5].

\section{An explicit definition for responsibility, more standard for jobs}

We should focus more on standardized management of job responsibility, further clarify and refine the responsibilities of each position and it should be easier to operate easily quantified appraisal. It is more appropriate to manage the talents by types, optimize the human resource which will be fully effective for the enterprises' development. For the definition of the responsibilities, we should avoid to be extensive generally. Human resource should put in place. In addition, the training system for talents is needed to help them do their duty and decrease the risk of brain drain. Besides, it needs scientific and reasonable configuration depending on the overseas experts' posts and corresponding research team. Exploration of relative dynamic mode of team management will help experts work better.

\section{More training program for high-level overseas talents}

Those high-level overseas talents come from all over the world that have different culture, ideas, values and working method which are quite different in China. For state-owned enterprises, it needs to provide more training program for them which will help them better understand the culture of state-owned enterprises, the mode of management of technology, the system of management of human resource, the definition of their responsibilities and the condition for research in China. Thanks to training program they will rapid adapt to us and play a very important role in enterprises. In particular, in planning of training, we must avoid formalism.

\section{Optimization of salary structure, perfectness the motivation system}

The motivation system can be optimized in two aspects: adjust salary structure, which means to adjust the fixed salary to the fixed plus incentive compensation model, set a certain proportion of incentive pay, 
in particular the long-term incentive pay which is good to the strategy of enterprises' human resource; set the appropriate rewards and punishments measures for high-level overseas talents which is related to the achievement assessment, increase the ratio of major project, national science and technology award, the international important awards, construction of national base and the high impact factors and high citation papers in related achievement assessment, translate the mode of expanding to the mode of innovation and create a suitable condition for research for talents. In one hand, we should motivate the enthusiasm of innovation of overseas talents; on the other hand we must avoid the high pay but low efficiency phenomenon. In the design of the motivation system, it is more important to setup some motivation in spirit than just in material. High proportion of the motivated payment is against to the development of human resource of overseas talents [6].

\section{Classification method for achievement assessment}

There are mainly two types of overseas returnee: one is researcher on the basis and the frontier discipline, the other is technological personnel to the production and manufacture. Consequently, the types of achievement assessment should classify according to their responsibilities. For the talents of research, we consider more on a long period evaluation and introduce academic expert evaluation system. For those talents, they need more time to do the research and need more freedom to think. For better playing talents' part of work, we ignore the short-term benefit and try to motivate their innovative abilities. For the talents of technology, when we set the quantitative indicator of achievement assessment, we strengthen the quality and the standard of performance assessment and weaken the quantitative assessment. We shall introduce regulations for experts to evaluate so that we can make full use of these talents' oversea working experience by putting their international point of view into practice. All these efforts will end up with bring about international-leveled state-owned enterprises with standard and well performing management system in terms of quality and regulations.

\section{Summary}

Overall, the management of overseas talents in the stated-owned enterprises still has a long way to go. It is on edge to change the current situation. We should pay more attention to scientific human resource planning; motivate system, training program and achievement assessment.

\section{Acknowledgement}

This research was financially supported by the National Science Foundation.

\section{References}

[1] Y.J. Li, X.J. Su, Deep think in the value of high-level overseas talents in state-owned enterprise, J. The management of human resource, (2012)89.

[2] Y.H. Wu, New strategy change in the multinational corporation, J. Development of talents, (2012).

[3] W.G. Pan, Creating a better condition for the introduction of high-level overseas talents, J. China Finance, 12 (2010) 86-87.

[4] The relationship between the measures of overseas talents and the Chinese characteristic system of talents, J. The reform and opening up, (2012) 5.

[5] Y.S. Ji, Positive introduction of overseas talents, J. International talent exchange, (2008) 4.

[6] J.Y. Wei, Y. Zhu, Exploration suggestion and measures of the introduction of high level overseas talents J. The human resource management, (2012) 157-158. 